yet recoverable illness-in 30 children of the original 41 this had lasted for over a year, and in no fewer than eight of them for over five years. It was even more disturbing to find how long their depression had gone undetected, often despite repeated clinical examinations. As these symptoms are fairly common among children of school age, there may well be a sizable group with a handicapping yet treatable depressive illness in the school population. A personality change in a child is too easily attributed to "growing up," and it is too readily assumed that the attention which his difficulties attract, whether aches and pains or behaviour disorders, affords him sufficient gratification. Yet once they had recovered with treatment these children were delighted to be well, and showed no regret for any lost parental attention to vanished symptoms.

In conclusion it appears plain that, despite the limitations and inaccuracies which inevitably accompany an outpatient drug trial such as this, antidepressant drugs are much more useful for the treatment of depressed children, whether with "functional " somatic symptoms or a "behaviour disorder," than is the phenobarbitone so often used.

Much more work is needed to clarify the clinical picture of depressive illnesses seen in childhood, and to differentiate and improve this technique of treatment; but the results in this preliminary study far exceeded expectations, and suggest that such further research will be well worth while.

\section{Summary}

The clinical symptoms of childhood depression are described. A double-blind cross-over trial showed that phenelzine and chlordiazepoxide are superior to phenobarbitone and an inert capsule in treating these childhood depressions. This finding was confirmed during further periods of clinical treatment. Many children recovered rapidly from illnesses of up to five years' duration, and the diagnosis had often been missed.

My thanks are due to Dr. Eliot Slater for his help and advice in the interpretation of the results, and to $m y$ colleagues in the departments of paediatrics and psychological medicine, who referred patients and helped me with this work.

\section{REFERENCES}

Connell, P. (1965). In Modern Perspectives in Child Psychiatry, edited by J. G. Howells, p. 421. London.

Frieze, M. (1965). Brit. med. ๆ., 2, 1489.

Pare, C. M. B., Rees, L., and Sainsbury, M. J. (1962). Lancet, 2, 1340. Poussaint, A. F., and Ditman, K. S. (1965). F. Pediat., 67, 283.

Reca de Acosta, T., Moreno de Taubenslag, I., and Kusnir, J. E. (1959). f. Soc. Ciénc. méd. Lisboa, 123, Suppl. p. 270.

Sargant, W., and Dally, P. (1962). Brit. med. F., 1, 6.

West, E. D., and Dally, P. J. (1959). Ibid., 1, 1491.

\title{
Trial of Ascorbic Acid in Senile Purpura and Sublingual Haemorrhages
}

\author{
G. ARTHUR,* M.B., CH.B.; J. A. MONRO, † M.B., B.S.; P. POORE, $\ddagger$ M.B., B.S.; W. B. RILWAN,§ M.B., B.S. \\ E. LA C. MURPHY, M.A., M.D., D.P.H.
}

Brit. med. F., 1967, 1, 732-733

Taylor (1965) noted that sublingual haemorrhages and purpuric lestons of the skin were common in elderly patients under his care, and after preliminary investigations put forward the hypothesis that these were manifestations of scurvy.

Hitherto, work such as that by Tattersall and Seville (1950) had been interpreted as meaning that senile purpura is not a manifestation of deficiency of vitamin C, and Andrews and Brook (1966) have reported no improvement in either sublingual haemorrhages or senile purpura on feeding supplements of ascorbic acid. They did, however, observe in their cases of sublingual haemorrhage (but not of purpura) a lower level of vitamin $C$ in white cells. A fairly long feeding trial with substantial amounts of ascorbic acid, as reported below, should therefore be of interest in helping to elucidate the cause of both conditions.

\section{Method}

As a first step Dr. Taylor was asked to demonstrate to the medical staff in the seven hospitals participating in the tests the purpuric and sublingual lesions which he regarded as manifestations of a scorbutic or subscorbutic state. (Figs. 1 and 2 illustrate examples.)

From the geriatric wards of seven hospitals 94 long-stay patients with lesions were selected for the trial in March 1966, but because of discharges and deaths only 77 remained at the end of the experiment; of these, 73 had senile purpura and 40 had petechial tongue lesions, 36 having both. Diagrams were drawn and descriptive notes made of the distribution and magnitude of lesions on the forearms and hands and also on the tongues at the beginning of the trial, and after intervals of two weeks, one month, and six weeks. Photographs were taken at the beginning and end of the trial (except in two hospitals where this proved impracticable). No patients with rheumatoid arthritis, diabetes mellitus, carcinoma, or any blood dyscrasia were included in the trial, nor any on supplements of vitamin C. The nursing staff were warned of the importance

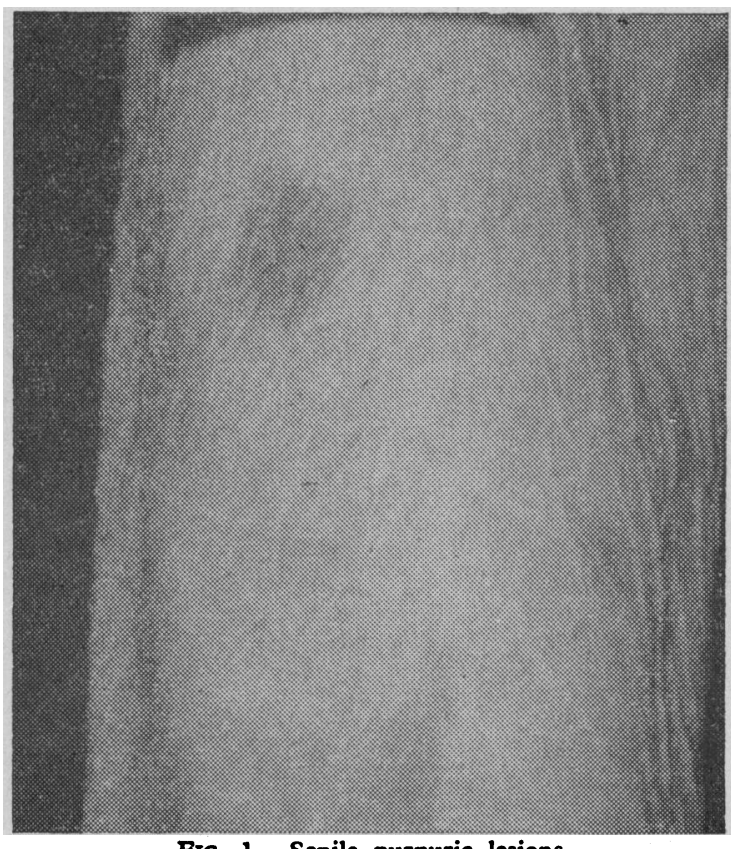

Fig. 1.-Senile purpuric lesions. 
of not allowing the patient "extras," over and above the standard hospital diet, of a sort that might supply additional vitamin C.

For one week a daily dose of 1,000 mg. of ascorbic acid was given to alternate patients (as two daily doses of $500 \mathrm{mg}$.), and inert (lactose) tablets were given twice daily to the other patients. For the next five weeks one tablet of $50 \mathrm{mg}$. was given daily to those who had been on vitamin-C tablets, while the "alternate" patients were given one inert tablet. The medical staff who assessed the progress of the lesions were kept in ignorance of the categories to which the patients were allotted.

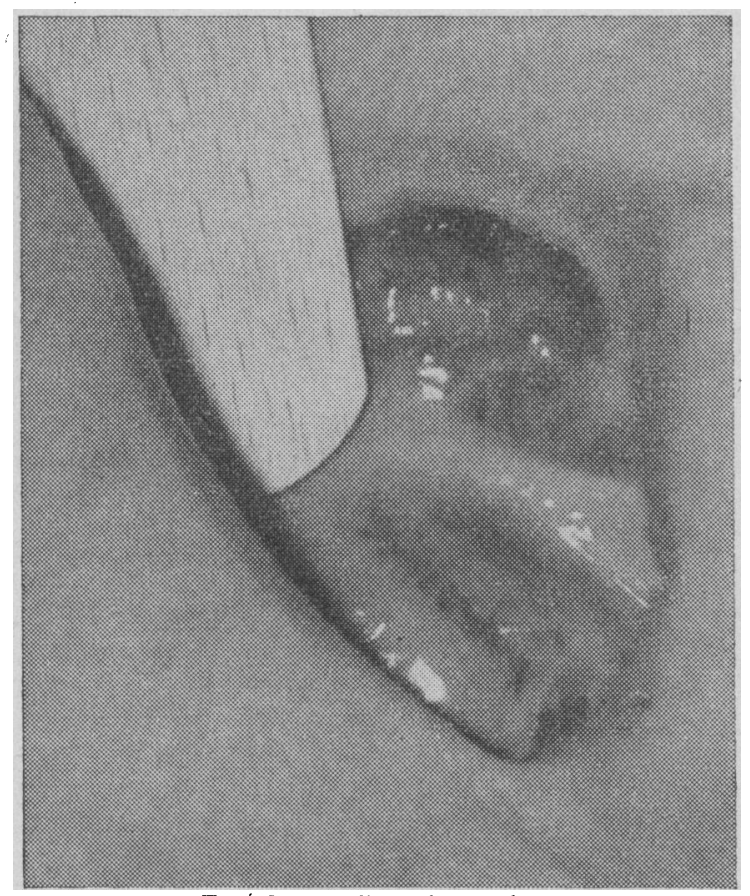

FIG.' 2.-Sublingual petechiae.

\section{Results}

The diagrams were examined after six weeks, and with the help of the photographs a decision was made on the patients to see if they were cured, better, unchanged, or worse. The results are given in the Table. Of those patients on the active tablets $55 \%$ were judged to have no change in senile purpuric lesions or to be worse, and of those on inert tablets $55 \%$ gave similar results.

In patients with sublingual haemorrhages two out of 21 $(9.5 \%)$ on the active tablets showed improvement ; out of 19 on the inert tablets two $(10.5 \%)$ were judged to be improved.

\section{Discussion}

In the classical experiments in which vitamin $C$ was administered to people with scurvy, response was characteristically rapid. When Lind (1743) gave the juice of two oranges and one lemon to two patients with scurvy, one was fit for duty at the end of six days. Crandon, Lund, and Dill (1940) gave an intravenous dose of $1,000 \mathrm{mg}$. daily to a subject depleted of vitamin C. There was obvious subjective improvement in 24 hours; and the scorbutic petechiae had faded considerably in six days and had gone in 12 to 14 days. In the Medical Research Council's (1953) experiment in Sheffeld, volunteers with clinical signs of scurvy who were given $10 \mathrm{mg}$. of vitamin C daily showed no fresh lesions after one week. The appearance of the skin became normal by the end of seven to nine weeks, but their gums took about 10 to 14 weeks to heal. When 20 mg. was given daily there was complete resolution of all scorbutic lesions in three weeks. It is thus obvious that what we have been observing cannot be classical scurvy.
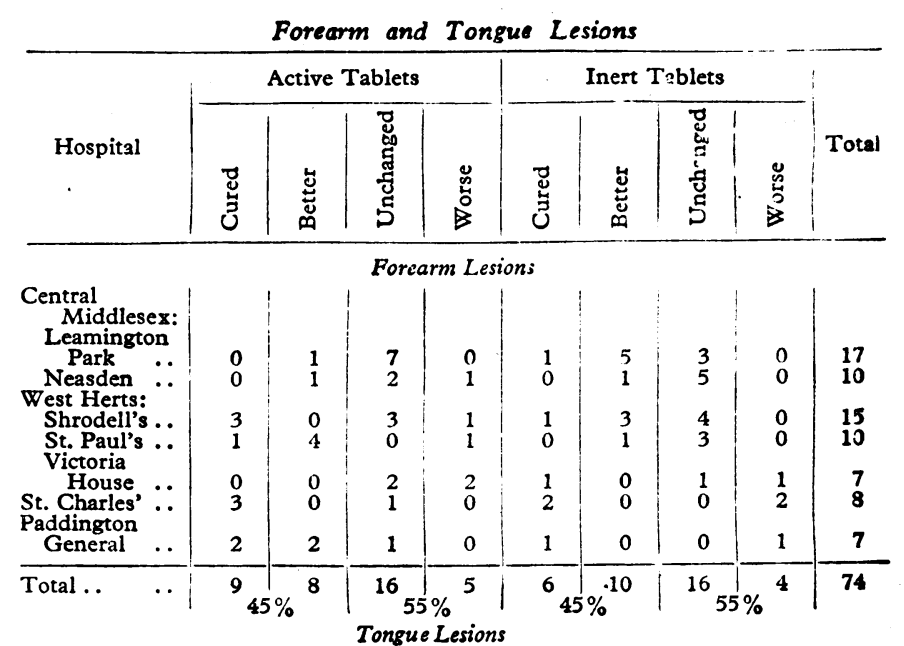

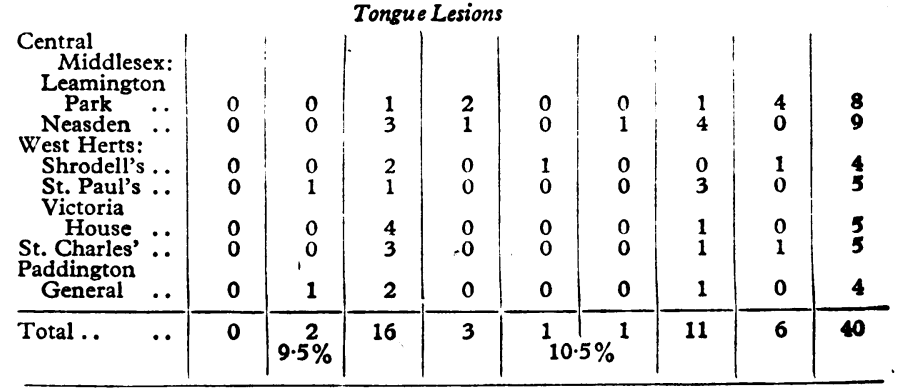

It is of course possible that long-standing vitamin-C deficiency in the elderly may not respond to treatment as quickly as does scurvy in younger subjects. The response to ascorbic acid was studied in the elderly by Bowers and Kubik (1965), who found that leucocyte vitamin-C levels in the elderly can be raised in about one to two weeks on $120 \mathrm{mg}$. of vitamin C daily to the same mean levels as in younger people. However, low leucocyte vitamin- $C$ levels in the elderly are obviously not necessarily proof of scurvy. Denson and Bowers (1961) noted that low levels of leucocyte vitamin $C$ in the elderly were not associated with excretion of abnormal phenolic acid, which had been found in frank scurvy.

Findings in the present study and that of Andrews and Brook (1966) and of Tattersall and Seville (1950) are to the effect that senile purpura is unlikely to be a manifestation of vitamin-C deficiency. The only indication to date that this may not also be true of sublingual haemorrhages comes from the finding of Andrews and Brook that the leucocyte vitamin-C levels are lower in patients with sublingual haemorrhages.

\section{Summary}

A vitamin-C feeding trial in geriatric patients showed that neither senile purpura nor sublingual haemorrhages responded to substantial amounts of ascorbic acid given over a period of six weeks.

We are indebted to the consultant geriatricians, Dr. A. D. Abdullah, of Central Middlesex Hospital Group, Dr. K. C. Rohinson, of West Herts Hospital Group, and Dr. A. I. Suchett. Kaye for the interest they took in the study, and also to the nursing staff for their invaluable help. We would also like to thank Vitamins Limited for supplying the tablets, and Mr. J. Richard for taking the photographs.

\section{REFERENCES}

Andrews, J., and Brook, M. (1966). Lancet, 1, 1350

Bowers, E. F and Kubik, M M. (1965) Brit. clin. Pract. 19, 141. Crandon, J. H., Lund. C. C., and Dill, D. B. (1940). New Engl. \%. Med. 223, 353 .

Denson, $\mathrm{K}$ W and Bowers, E. F. (1961). Clin. Sci., 21, 157.

Medical Researcb Council (1953). Spec. Rep. Ser., No. 280

Tattersall, R. N, and Seville, R. (1950). Quart. \%. Med., 19, 151.

Taylor, G. F. (1965). Personal communication and Manchester Guardien. May 11 . 